\title{
Extent of Solubilization of $\alpha$-Cellulose and Hemicellulose of Low-protein Teff Hay by Pure Cultures of Cellulolytic Rumen Bacteria
}

\author{
By S. G. KOCK AND A. KISTNER \\ National Chemical Research Laboratory, \\ South African Council for Scientific and Industrial Research, \\ Pretoria, South Africa
}

(Accepted for publication I5 November 1968)

SUMMARY

Ten isolates belonging to the genus Butyri vibrio and two each of Ruminococcusalbus, $R$. flavefaciens and an unidentified Clostridium sp. were isolated from high dilutions of rumen fluid from sheep conditioned to low-protein teff hay. The butyrivibrios solubilized between Ioand $37 \%$ of the $\alpha$-cellulose of the hay (average $21 \%$ ). The two isolates of Ruminococcus albus degraded 43 and $56 \%$ of the $\alpha$-cellulose and the two of $R$. flavefaciens 39 and $66 \%$, while the two Clostridium cultures achieved only 10\% degradation. Hemicellulose degradation by the Butyrivibrio isolates was between 25 and $67 \%$ (mean $48 \%$ ) and that by the four Ruminococcus cultures between 47 and $65 \%$. One of the Clostridium cultures solubilized $21 \%$ and the other $51 \%$ of the hemicellulose. The butyrivibrios appear capable of contributing a greater share towards cellulose digestion in ruminants on low-protein hay than has been inferred from qualitative in vitro tests for cellulolysis, using refined cellulose preparations; they are probably less active than the ruminococci.

\section{INTRODUCTION}

Gram-negative curved rods were repeatedly found to be either the most abundant or among the most abundant cellulolytic bacteria in the rumen of sheep conditioned to low-protein teff (Eragrostis tef) hay (Gilchrist \& Kistner, 1962; Gouws \& Kistner, 1965; Van Gylswyk, 1968). These rods were identified as belonging to the genus Butyrivibrio (Bryant \& Small, 1956) and were subdivided into two groups, one of which was closely related to $B$. fibrisolvens while the other was somewhat more heterogeneous and differed in several respects from the only other species of the genus, B. alactacidigens, proposed by Hungate (1966) (Shane, Gouws \& Kistner, 1968). Although the isolates of both groups originated from colonies in primary cultures in cellulose agar films which had produced zones of cellulolysis, the majority did not give rise to a visually detectable disappearance of either cotton-wool or filter paper cellulose in liquid media containing $0.2 \%(\mathrm{w} / \mathrm{v})$ of these substrates. This appeared to be at variance with their supposed role as important cellulose digesters in sheep conditioned to low-protein teff hay. It seemed feasible that these refined forms of cellulose were less suitable substrates for the butyrivibrios than the forage fed to the sheep from which they were isolated. A selection of isolates, representing the two groups of Butyrivibrio mentioned above, were therefore tested for their ability to solubilize $\alpha$-cellulose 
and hemicellulose in the form present in finely ground teff hay. Hemicellulose was included in the study since all the isolates had been found to ferment corn cob xylan. Two strains of an unidentified Clostridium sp. which had also produced zones of cellulolysis in the primary cellulose agar cultures but shown little cellulolytic activity in subsequent tests in liquid medium, and two strains each of Ruminococcus albus and $R$. flavefaciens which had produced visually detectable solubilization of either filter paper or cotton-wool cellulose, were tested in parallel with the Butyrivibrio isolates.

\section{METHODS}

Substrate. A sample of the same batch of teff hay as was fed to the sheep from which the bacterial cultures were isolated was used as substrate. It contained $36 \cdot 2 \% \alpha$-cellulose and $40.5 \%$ hemicellulose. The hay was ground in a Wiley mill to pass a 44-mesh sieve. Lipid was removed by extraction with ethanol-benzene $(2: \mathrm{I}, \mathrm{v} / \mathrm{v})$ for $90 \mathrm{~min}$. in a Soxhlet extractor.

Test medium. One g. portions of well-mixed, air-dried hay were placed in $600 \mathrm{ml}$. bottles, $200 \mathrm{ml}$. portions of basal minerals-rumen fluid medium, as used by Kistner \& Gouws (1964) for fermentation tests, were added, the bottles were purged with oxygenfree $\mathrm{CO}_{2}$, sealed with rubber stoppers and sterilized at $\mathrm{I} 2 \mathrm{I}^{\circ}$ for $25 \mathrm{~min}$.

Organisms. The ten cultures of Butyrivibrio spp., and two each of Ruminococcus albus, $R$. flavefaciens and the unidentified Clostridium sp. used in this study, have been described by Shane et al. (1968). The cultures were maintained on minerals-rumen fluid-cellobiose agar. The surface growth of an $18 \mathrm{hr}$ slant culture, suspended in $0.5 \mathrm{ml}$. anaerobic phosphate buffer (Kistner \& Gouws, 1964), served as inoculum for a test in duplicate. The inoculated test media were incubated at $38^{\circ}$ for 3 weeks, to ensure that incubation time did not limit the extent of solubilization of $\alpha$-cellulose and hemicellulose. Uninoculated controls were similarly treated.

Analytical procedures. On completion of the incubation period, the cultures were quantitatively transferred to plastic centrifuge bottles and centrifuged at $1200 \mathrm{~g}$ for $25 \mathrm{~min}$. The supernatant fluid was discarded, the sediment suspended in $96 \%(\mathrm{v} / \mathrm{v})$ ethanol, transferred to $100 \mathrm{ml}$. plastic centrifuge tubes and recentrifuged. The sediment was treated once more with ethanol to dehydrate bacterial slime which tended to clog the sintered glass filter crucibles in subsequent procedures. Alpha-cellulose and hemicellulose were determined by the procedure described by Wise, Murphy \& D'Addieco (1946) for the isolation of holocellulose and $\alpha$-cellulose from wood. However, in view of the small weight of sample remaining after incubation and the lower proportion of lignin, the residual hay was suspended in $128 \mathrm{ml}$. of deionized water and treated twice, instead of three to four times, with one-third of the quantities of glacial acetic acid and sodium chlorite used by these workers. The holocellulose was dried at $110^{\circ}$ for $4 \mathrm{hr}$ before weighing. For the present purpose, hemicellulose fractions A and B were not determined separately, nor were the hemicelluloses isolated. Instead, hemicellulose content of the hay was calculated from the loss in weight on treating the isolated holocellulose with $24 \%$ (w/v) $\mathrm{KOH}$ solution at $20^{\circ}$.

The extent of solubilization of $\alpha$-cellulose and hemicellulose was calculated with reference to the analytical values obtained on uninoculated control media after incubation. 
RESULTS AND DISCUSSION

The means of duplicate determinations of the extent of solubilization of $\alpha$-cellulose and hemicellulose by the 16 cultures are shown in Table $\mathrm{I}$. Under the conditions of the in vitro test, the Butyrivibrio isolates solubilized between Io and $37 \%$ of the $\alpha$-cellulose of the hay, with an average value of $21 \%$. There was no marked difference in the cellulolytic potential between the two groups. It would therefore appear that the butyrivibrios can play a significant part in the digestion of cellulose in the rumen of sheep under conditions where they are the predominant cellulolytic bacteria isolated. The extent of cellulose digestion by the pure cultures used in the present study is, however, considerably less than that found in vivo in four sheep conditioned to lowprotein teff hay, namely a mean of $57 \%$ (van Gylswyk, 1968). It may be that the activity of these organisms is increased in vivo by synergism with non-cellulolytic

Table I. Extent of solubilization of a-cellulose and hemicellulose of low-protein teff hay by pure cultures of cellulolytic rumen bacteria isolated from sheep conditioned to such hay

\begin{tabular}{lcc} 
& \multicolumn{2}{c}{ Extent of solubilization (\%) } \\
\cline { 2 - 3 } $\begin{array}{c}\text { Cultures } \\
\text { Butyrivibrio, group I }\end{array}$ & $20 \cdot 5$ & Hemicellulose \\
CE 47 & $27 \cdot 1$ & $49 \cdot 5$ \\
CE 5I & $17 \cdot 9$ & $66 \cdot 8$ \\
CE 52 & $22 \cdot 8$ & $54 \cdot 8$ \\
CXS I8 & & $44 \cdot 8$ \\
Butyrivibrio, group 2 & $10 \cdot 0$ & \\
CE 64 & $37 \cdot 1$ & $25 \cdot 3$ \\
CE 65 & $21 \cdot 7$ & $61 \cdot 1$ \\
CE 66 & $14 \cdot 7$ & $49 \cdot 6$ \\
CE 78 & $17 \cdot 4$ & $31 \cdot 5$ \\
6B & $24 \cdot 9$ & $40 \cdot 7$ \\
7 A & & $53 \cdot 0$ \\
Clostridium sp. & $10 \cdot 1$ & \\
CE 3 & $10 \cdot 7$ & $20 \cdot 6$ \\
CE 30 & & $51 \cdot 2$ \\
Ruminococcus albus & $43 \cdot 4$ & \\
CE 54 & $56 \cdot 0$ & $47 \cdot 9$ \\
CXS 60 & & $56 \cdot 3$ \\
R. flavefaciens & $66 \cdot 2$ & $64 \cdot 6$ \\
CE 77 & $38 \cdot 9$ & $47 \cdot 2$ \\
4A &
\end{tabular}

species. Dehority \& Scott (1967) have shown such a synergistic effect on degradation of cellulose in different forages in vitro by combining a strain of the hemicellulolytic, but non-cellulolytic organism Bacteroides ruminocola with any of two strains of Ruminococcus flavefaciens, one of $R$. albus and one of B. succinogenes. However, in the teff hay-fed sheep studied by van Gylswyk (I968), the higher cellulose digestion could have been due to large numbers of ruminococci which were also present and which, the present results show, are more active cellulolytically than the butyrivibrios. Unfortunately, no figures for percentage degradation of cellulose are available for the sheep examined by Gilchrist \& Kistner (1962) in which butyrivibrios were the predominant cellulose-digesting bacteria.

The two isolates of Ruminococcus albus degraded 43 and $56 \%$ of the $\alpha$-cellulose 
present in the hay samples and the two strains of $R$. flavefaciens 39 and $66 \%$. That ruminococci are more active than butyrivibrios in vivo as well as in vitro is indicated by the results of van Gylswyk (1968), who found that the percentage digestion of cellulose of low-protein teff hay increased as the percentage proportion of ruminococci among the cellulolytic bacteria increased as a result of supplementation. The highest percentage of cellulose solubilized by a Ruminococcus isolate was $66.2 \%$ by strain CE 77. This is very similar to the highest value reported by Dehority \& Scott (1967) for their most active strain of $R$. flavefaciens, when grown on timothy hay cut at boot stage. It is also very close to the mean percentage of teff hay $\alpha$-cellulose digested in vivo $(72 \%)$ when the hay was supplemented with urea and the potassium salts of isobutyric, 2-methylbutyric, isovaleric and $n$-valeric acids. In this case, about $90 \%$ of the cellulolytic population of the rumen consisted of ruminococci (van Gylswyk, 1968). Thus, for this species, the in vitro results are a fair reflexion of their capacity to digest cellulose in vivo.

The clostridia appear to be of little importance in the digestion of cellulose in sheep on teff hay rations, since not only do they occur only sporadically in high numbers, but their ability to attack native cellulose is limited.

The extent of hemicellulose degradation by the Butyrivibrio isolates was between 25 and $67 \%$ (mean $48 \%$ ) and that by the four Ruminococcus cultures between 47 and $65 \%$. One of the Clostridium cultures solubilized $21 \%$ and the other $51 \%$ of the hemicellulose present in the samples. The fact that the butyrivibrios and ruminococci have similar activity in degrading teff hay hemicellulose means that the increase in digestibility of this component in sheep on supplemented teff hay diets cannot be explained by the increase in the preponderance of ruminococci in the rumen (van Gylswyk, 1968). Other organisms which degrade hemicellulose, but not cellulose, may be involved.

The authors wish to thank the Chief, Veterinary Research Institute, Onderstepoort, for facilities for carrying out this work. Appreciation is expressed to Mr J. G. de Wet for advice on the analytical procedures.

This paper forms part 6 of a series on 'Bacteria of the ovine rumen'.

\section{REFERENCES}

Bryant, M. P. \& Small, N. (1956). The anaerobic monotrichous butyric acid-producing curved rod-shaped bacteria of the rumen. J. Bact. 72, 16.

Dehority, B. A. \& SCOTT, H. W. (1967). Extent of cellulose and hemicellulose digestion in various forages by pure cultures of rumen bacteria. J. Dairy Sci. 5o, 1136.

GiLCHRIST, F. M. C. \& KISTNER, A. (1962). Bacteria of the ovine rumen. I. The composition of the population on a diet of poor teff hay. J. agric. Sci., Camb. 59, 77.

Gouws, L. \& KisTNER, A. (1965). Bacteria of the ovine rumen. IV. Effect of change of diet on the predominant type of cellulose-digesting bacteria. J. agric. Sci., Camb. 64, 51 .

Hungate, R. E. (1966). The Rumen and its Microbes, Ist ed. New York and London: Academic Press.

KISTNER, A. \& Gouws, L. (1964). Cellulolytic cocci occurring in the rumen of sheep conditioned to lucerne hay. J. gen. Microbiol. 34, 447.

Shane, B. S., Gouws, L. \& KistNeR, A. (1968). Cellulolytic bacteria occurring in the rumen of sheep conditioned to low-protein teff hay. (In the Press.)

van Gyswyk, N. O. (1968). The Cellulolytic Rumen Bacteria of Sheep Fed Supplemented Hay Diets. M.Sc. thesis, University of Pretoria.

WISE, L. E., MURPHY, M. \& D'ADDIECO, A. A. (1946). Chlorite holocellulose, its fractionation and bearing on summative wood analysis and on studies on the hemicelluloses. Paper Trade $J$. 122, 35. 